\title{
A PARTICULLRIDADE COMO EIXO CENTRAL NA ESTÉTICA DE LUKÁCS
}

\section{THE PARTIICLLRITY AS CENTRAL AXIS IN AESTHETICS OF LUKÁCS}

SANTOS, Deribaldo. A particularidade na estética de Lukács. São Paulo: Instituto Lukács, 2017

\section{Edson Roberto de Oliveira Silva'}

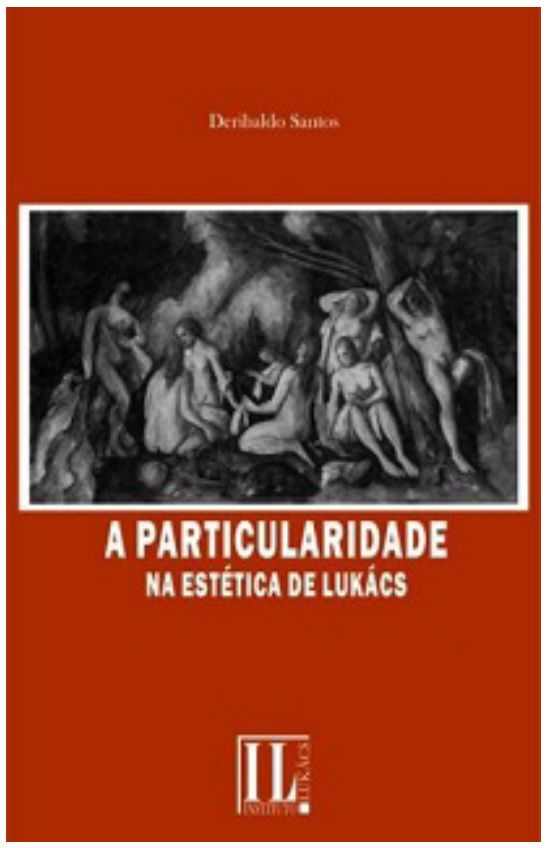

"A particularidade na Estética de Lukács" de Deribaldo Santos, publicado pelo Instituto Lukács (IL), com primeira edição no ano 2017, trazendo os principais conceitos da obra de maturidade de György Lukács, elaborada de forma mais bem-acabada em a Estética 1. 0 autor se propõe a sistematizar as categorias lukacsiana contida na obra do filósofo, deixando-as mais acessíveis para o entendimento e direcionando-as para o público interessado no pensamento Lukács e para quem se interesse e estude estética. O estudioso da particularidade em Lukács tem publicado pela editora do IL "Estética em Lukács - A criação de um mundo para chamar de seu", além deste, outros livros de cunho literário e na área de educação.

Em seu livro, Santos se propõe a expor os conceitos estéticos de Lukács de forma didática para seus leitores, preocupação coerente para um intelectual que tem sua formação em pedagogia e educação. Com essa preocupação do autor, temos em tela uma estrutura fluida e bem amarrada, dividida em três capítulos, tendo cada um em média quatro subcapítulos, que demonstram de forma sistemática transições entre categorias. Sendo assim, 0 primeiro capítulo tem o objetivo de mostrar como as categorias trabalho, cotidiano e arte tem suas materialidades efetivas na vida comum e como são formas de objetivação humana; articular o distanciamento e aproximações ente a arte e a ciência; por fim, qual é a gênese do desligamento dos reflexos estéticos na realidade. No segundo capítulo, o autor articula a centralidade da categoria 1 Mestrando na Pós-Graduação em História da UNESP de Assis - SP. Atualmente é bolsista CAPES. E-mail para contato: edoliviera89@gmail.com. 
da particularidade para a estética marxista, passando por uma demonstração teórico-metodológica desta, apontando para a importância de J.W. Goethe para a formulação da categoria em questão e o esclarecimento de sua peculiaridade. No terceiro e derradeiro capítulo, o autor trata da concepção de forma-conteúdo e essência-aparência, pontos cruciais para a compreensão da dialética da particularidade estética. $O$ estudioso da particularidade em pouco mais de cem páginas coloca em tela sua proposta: demonstrar o movimento dialético interno das categorias lukacsiana, atreladas à realidade concreta.

Para Ranieri Carli, o conceito de particularidade para Lukács é elemento "imposto ao estético pela própria realidade objetiva" que "ocorre do fundamento terreno da arte: a criação de uma imagem aproximativa que traduza em destinos humanos concretos as forças sociais de época e lugar determinados" (CARLI, 2012, p. 117). Segundo esse outro estudioso, o filosofo húngaro defende que a partir da centralidade do particular a universalidade ganha caráter concreto, deixando de ser abstrato, tal qual o singular passa a ter um sentido, deixando de ser avulso. Assim, em sua Estética 1 "a situação do particular vem confirmar a não imediaticidade do reflexo estético" (CARLI, 2012, p. 117). O húngaro, para Carli, propõe-se à formulação de uma teoria estética marxista voltada para o caráter organizativo da particularidade na obra de arte, tendo como ponto de partida uma visão histórica e crítica do pensamento filosófico alemão, desde Kant, passando por Schelling, Hegel e Goethe, chegando a Marx e Engels.

Lukács até o fim de sua vida se dedicou a entender a obra de arte em relação à ciência, como essas duas formas de representação do mundo se relacionam entre si e expressam de formas diferentes a mesma realidade efetiva. Esse esforço é elaborado através das lentes teórico-metodológica marxistas. $O$ que Santos nos mostra em seu livro é a importância da categoria de particularidade para a produção e entendimento das obras arte, assim como a importância dessa categoria para o método cientifico. $\mathrm{O}$ autor faz uma análise interna das obras de Lukács - Introdução a uma Estética Marxista e Estética 1 - em que se propõe mostrar a relação entre o Particular, o Singular e o Universal, levando em consideração as várias categorias que são essenciais para o movimento do particular ao universal nas obras artísticas e na ciência.

A categoria de particularidade para Santos é o que permite analisarmos a realidade concreta na sua mais complexa determinações, pois essa categoria é o ponto principal para o movimento dialético tanto da obra de arte como da ciência. Lukács, em uma das obras analisadas por esse estudioso, coloca da seguinte forma "para entender a diferença decisiva entre reflexo científico e reflexo estético, tivemos de sublinhar que o particular, que figurava no primeiro como 'campo' de mediação, deve se tornar no segundo o ponto central organizador" (LUKÁCS, 1978, p. 173), com isso fica claro a diferença da categoria de particular na metodologia de uma obra artística e essa categoria em relação à analise cientifica.

A categoria de reflexo estético é colocada no livro de Santos como fruto da realidade unitária, assim, a entrada para a representação da realidade a partir desse reflexo é o próprio cotidiano, onde ocorrem as objetivações superiores. Sendo na cotidianidade que ocorrem as contradições do mundo prosaico e nesta instância encontramos as características fundamentais da vinculação entre teoria e prática. 0 estudioso da particularidade nos mostra que Lukács coloca o cotidiano como preponde- 
rante sobre o pensamento científico e que desse solo partem as formulações de questões que serão resolvidas cientificamente. $\mathrm{O}$ autor nos mostra que, na visão do filósofo húngaro, a ciência e a arte entram na divisão social capitalista do trabalho, formando os vários campos das artes e da ciência modernas, e que nessa formação histórica da divisão social do trabalho isso é o que determina a divisão entre o pensar e o fazer, ou seja, somente com a consolidação da modernidade como um período histórico que detém maior complexidade de determinações há também a separação plena entre teoria e práxis.

Seguindo Lukács, Santos coloca que a existência do objeto a ser analisado cientificamente é independente da consciência do sujeito. Assim, partindo de um ponto de vista materialista dialético, que atribui cientificidade à historiografia, esta, por sua vez, tomaria a própria história como um processo real e efetivo, independente da consciência do historiador. Desse modo, a função da História como ciência seria o esforço de desantropomorfizar o objeto que está sendo pesquisado, tal como qualquer ciência modernamente estabelecida. A desantropomorfização, em termos gerais, é a retirada de características atribuídas humanamente ao objeto e que partem de um senso comum cristalizado. Com isso, o reflexo científico tem a função de representar a realidade tal como ela é em suas várias determinações inerentes, com realidade independente em relação ao conhecimento.

Em contraponto, o reflexo estético é a antropomorfização da realidade, isto é, tem a função de atribuir a ela maior gama de características humanas, deixando sua representação mais enriquecida, fazendo o movimento de articulação entre a inerência da obra de arte e a externalidade da realidade concreta. Toda a forma de reflexo - no caso, estético e cientifico - , são determinados, como demonstra o estudioso, partindo de Lukács, por um hic et nunc (aqui e agora) que já é histórico em sua gênese. $O$ autor nos mostra que "cada reflexo, artístico ou cientifico, está carregado de ponderações materiais e temáticas impressas pelo espaço temporal de sua consumação" (SANTOS, 2017, p. 25). Com isso, demonstrando que há na interpretação de Lukács uma defesa da imanência do objeto, o qual é uma exigência insolúvel ao conhecimento científico.

Como imanência do objeto, o autor categoriza tudo aquilo que é indissociável do objeto investigado pelo cientista. Assim, à ciência, com o seu método, caberia se aproximar da realidade imanente a esse objeto, isto é, a ciência - em seu movimento interno — só é capaz de se aproximar da realidade e isso é uma forma necessária para que haja um processo de atualização constante dela mesma, determinado pelo objeto, sendo este independente da consciência do sujeito; no processo em questão, também se proporciona rastros a serem seguidos posteriormente, e esses rastros se estendem ad infinitum.

A Estética, relacionada à ciência do belo, enquanto efetividade sensorial ${ }^{2}$, ou seja, relativa aos cinco sentidos humanos, também tem a funcionalidade de analisar a sensação humana dentro dos vários âmbitos particulares da realidade cotidiana, o filósofo alemão G. W. F. Hegel coloca o termo estética em relação ao âmbito da arte dizendo

O nome estética decerto não é propriamente de todo adequado para este objeto, pois "estética" designa mais precisamente a ciência do sentido, da sensação [Empfinden].

2 Ver mais em: GREUEL, Marcelo da Veiga. Da “Teoria do Belo” à “Estética dos Sentidos” - Reflexões sobre Platão e Friedrich Schiller. In Anuário de Literatura 2, 1994. pp. 147-155. 
Com este significado, enquanto uma nova ciência ou, ainda, enquanto algo que deveria ser uma nova disciplina filosófica, teve seu nascimento na escola de Wolff, na época em que na Alemanha as obras de arte eram consideradas em vistas das sensações que deveriam provocar, como por exemplo as sensações de agrado, de admiração, de temor, de compaixão e assim por diante (HEGEL, 2015, p. 27).

Santos irá diferenciar a arte da religião, para o autor a primeira tem como imanente o humano, assim, os seres humanos em sua atividade seriam o núcleo para a produção artística. No caso da segunda, a religião, o investigador demonstra que na concepção de Lukács ela também depende do homem para existir, porém a sua diferença com a arte e com a ciência está na sua orientação ao transcendental, ou seja, ela está para além do hic et nunc (aqui e agora). Podemos fazer a mesma relação com a ciência, que, assim como a arte tem como núcleo a atividade humana, e diferente da religião, não tem orientação ao transcendental. Desse modo a arte e a ciência tem como núcleo o mesmo objeto, o homem, e por esse mesmo núcleo ambas são desenvolvidas. Nessa concepção essas três formas de representação do mundo, arte, ciência e religião, para o filósofo húngaro dependem do sujeito para existir, ou seja, depende da pratica humana na sua forma mais aberta possível, essas representações estão totalmente atreladas, para Santos e Lukács, com a divisão social capitalista do trabalho.

A divisão social capitalista do trabalho é uma relação social que irá determinar as duas principais formas de reflexo do mundo, a arte e a ciência. Santos afirma que para Lukács essa divisão social historicamente determinada cria na representação do mundo um estreitamento. O autor defende que para Lukács os sentidos humanos, apesar de serem in natura, são desenvolvidos historicamente para atender necessidades socialmente constituídas, mas, com a divisão social do trabalho haveria um estreitamento da visão de mundo, o que direcionaria o foco para pontos isolados; isso se intensifica na sociedade moderna.

A partir da observação do fenômeno de estreitamento dos sentidos humanos, o estudioso constata que Lukács concebe o homem em duas formas: o "homem-inteiro" e o "homem-inteiramente". O primeiro nada mais é que o homem que está vinculado diretamente ao seu cotidiano e que está inserido nele de forma inteira, pois esse sujeito é parte determinante e determinada pelas relações sociais. O segundo é o homem que tem acesso a um mundo qualitativamente distinto do próprio cotidiano, isto é, o homem que entra em contato com a obra de arte que expressa a universalidade mediante uma particularidade, esta última só pode ser humana e o contato com essa dimensão da experiência é o que proporciona ao homem não ser mais "inteiro", mas sim estar no mundo "inteiramente", pois ele teve acesso a uma particularidade que atinge universalidade e o coloca em contato com a natureza humana propriamente dita. Um exemplo desse processo seria a empatia, ou seja, reconhecer o sentimento do outro e se reconhecer neste.

Santos, partindo de Lukács, mostra-nos que há uma relação oposta entre as categorias de singular e universal, essa forma de interação só pode ser sanada pela categoria do particular, que faz o papel de mediação e proporciona a interação entre as duas primeiras categorias. Assim, o particular é colocado também como uma categoria que atinge o universal, dirá Lukács em Introdução a Estética Marxista: "o processo pelo qual as categorias se resolvem e se transformam uma na outra 
sofre alterações: tanto a singularidades quanto a universalidade aparecem sempre superadas na particularidade" (LUKÁCS, 1978, p. 161).

O estudioso atesta que em Lukács todo o fenômeno originário é igual à particularidade, que é o seu ponto de mediação entre o singular e o universal. Do mesmo modo o autor colocará que para os marxistas a prioridade se encontra na realidade objetiva, em que está o movimento real, o que é fundamental à dialética materialista, e nota ainda que já no âmbito da estética a particularidade é um ponto em movimento, como dirá Lukács

A descoberta de Goethe, sobre o papel da categoria de particularidade na estética, não tem aparentemente muita importância: o movimento no qual o artista reflete a realidade objetiva culmina, fixa-se, recebe forma no particular, e não como no conhecimento cientifico, de acordo com suas finalidades concretas - no universal ou no singular. O conhecimento ligado à pratica cotidiana se fixa em qual quer ponto, a depender de suas tarefas concretas e práticas. O conhecimento cientifico ou a criação artística (bem como a recepção estética da realidade, como na experiência do belo natural) se diferenciam no curso do longo desenvolvimento da humanidade, tanto nos limites extremos como nas fases intermediarias. (LUKÁCS, 1978, p. 161)

Essa concepção de relação entre particular e universal, tem forma unitária no tema da relação entre forma e conteúdo. Para Lukács "no interior da comunidade de conteúdo e forma, são também comuns[...], as categorias de singularidade, particularidade e universalidade" (LUKÁCS, 1978, p. 161). Santos, tomando esse posicionamento de Lukács, divide em sua exposição a forma na ciência, que tem a obrigação de se afastar de um senso comum, da forma na estética, que tem sempre de estar atrelada a um conteúdo. Assim, o autor defende que o "processo técnico é fundado tendo como base o conhecimento imanente das leis naturais que independem da consciência humana" (SANTOS, 2017, p. 71), dessa forma na ciência o desenvolvimento da técnica ganha uma afirmação, sua objetividade procura aproximar-se da realidade concreta, isso é pensado pelo filósofo como reflexo da realidade. O reflexo artístico em seu desenvolvimento tem a funcionalidade de representar os distintos particulares dos seres humanos e tem como proposta capturar a essência dos novos fenômenos que se efetivam nessa realidade objetiva e sua forma tem que, de alguma maneira, evocar a experiência cotidiana, assim, o típico irá representar a verdade da forma. No reflexo cientifico o conteúdo precisa se fixar e se aprofundar na imediaticidade sensível das formas fenomênicas. A ciência em A particularidade na estética de Lukács é o aprofundamento da dialética entre necessidade e contingencia. A categoria do particular, defendida nesse livro, tem a capacidade de abraçar o mundo na sua inteireza, interna e externa.

Uma das maneiras da ciência burguesa refletir a realidade, segundo Lukács e o autor que se propõe a estudá-lo, é excluindo a importância da particularidade no método cientifico e isolando o singular de sua relação com o universal, assim, essa ciência vigente exclui o centro móvel que ordena a relação entre singular e universal. Um exemplo disso é a visão historiográfica predominante na contemporaneidade, que retira a centralidade da luta de classes do processo histórico e obscurece o proletariado como particularidade da sociedade moderna, particularidade esta que é de fundamental importância para o entendimento do processo sob o qual se ergue essa formação social, pois é por sua submissão que se garante a conservação do sistema de divisão social do trabalho já 
consolidado, que é o sistema capitalista.

Deribaldo dirá que "o reflexo artístico, ao criar suas refigurações da realidade, transforma o ser em si objetivo em um ser para nós de um mundo representado unicamente na individualidade da obra de arte" (SANTOS, 2017, p. 101). Desse modo o autor nos coloca que para Lukács, o par forma e conteúdo, opera no campo estético para uma distinção entre consciência e autoconsciência. O autor colocará que somente na esfera da estética a autoconsciência ganha um valor substantivo e que se expressa em dois sentidos, o primeiro é como um valor pessoal do objeto representado e depois como valor pessoal do modo de representação dessa realidade. Essas qualidades, em seu livro, são colocadas como o que despertam a autoconsciência, ela é aberta com uma retomada dos caminhos da humanidade percorridos, que aparecem por meio da rememoração, ou seja, pela "memoria". Dirá:

Como memoria, ou seja, como "recordação" do caminho que a humanidade, as pessoas e as situações percorreram ou irão percorrer; das virtudes e vícios do mundo interno e externo dos homens que, por sua vez, dá o ponto de partida para o desdobramento dinâmico, para o seio da contraditoriedade dialética, no qual o gênero humano levantou-se ao que hoje é e ao que poderá vir a ser (SANTOS, 2017, p. 102).

A autoconsciência da humanidade encontra na arte um modo adequado e evoluído dignamente, essa autoconsciência para o autor é "o correto reflexo do real, que existe independentemente da consciência individual, a imersão do sujeito na realidade, é o pressuposto imprescindível e fundamental de toda autoconsciência da humanidade" (SANTOS, 2017, p. 104).

Deribaldo Santos abordar sinteticamente a importância da categoria da particularidade para Lukács, partindo da análise interna do livro Estética 1. Isso é feito com uma exposição bastante didática do debate teórico-metodológico, o que ilustra bem a diferença entre a elaboração artística e a análise científica da realidade. Assim, o autor demonstra que as categorias abordadas no âmbito da filosofia lukacsiana, tais como: o reflexo; cotidiano; divisão social do trabalho; o objeto como independente da consciência do sujeito; antropomorfização e desantropomorfização; hic et nunc (aqui e agora); imanência; diferenciação entre a arte e a religião; homem-inteiro e homem-inteiramente; forma e conteúdo; em suas relações umas com as outras, são de grande importância para a apreciação da especificidade da categoria de particularidade como mediadora na análise científica, promovendo, nessa esfera, a articulação entre singular e universal, e na esfera da arte servindo como força organizadora interna das obras individuais. Por fim, o estudioso traz a possibilidade de entendimento da articulação entre as três categorias de singular, particular e universal para a história da filosofia da estética.

\section{REFERÊNCIAS}

CARLI, Ranieri. 4. O Particular como Categoria central da Estética. In CARLI, Ranieri. A estética 
de György Lukács e o Triunfo do Realismo na literatura. Rio de Janeiro: Editora UFRJ, 2012.

GREUEL, Marcelo da Veiga. Da "Teoria do Belo" à "Estética dos Sentidos" - Reflexões sobre Platão e Friedrich Schiller. In Anuário de Literatura 2, 1994. pp. 147-155.

HEGEL, G. W. F. I. Delimitações da Estética e Refutação de Algumas Objeções contra a Filosofia da Arte. In HEGEL, G. W. F. Curso de Estética I. Tradução de Marco Aurélio Werle. $2^{\circ}$ ed. rev. 1. Reimpr. São Paulo: Editora da Universidade de São Paulo, 2015.

LUKÁCS, Georg. V - O Particular como categoria central do Estético In. Introdução a Estética Marxista. Tradução de Carlos Nelson Coutinho e Leandro Konder $2^{\circ}$ edição. Rio de Janeiro. Civilização Brasileira, 1978.

MARX, Karl. Crítica da filosofia do direito de Hegel - Introdução. In Critica da filosofia do direito de Hegel. Tradução de Rubens Enderle e Leonardo de Deus. $3^{\circ}$ edição. São Paulo: Boitempo, 2013.

SANTOS, Deribaldo. A particularidade na Estética de Lukács. $1^{\circ}$ Edição. São Paulo: Instituto Lukács, 2017.

RECEBIDO EM: 20/10/2019

APROVADO EM: 10/11/2019 